\title{
Hsp70 localizes differently from chaperone Hsc70 in mouse mesoangioblasts under physiological growth conditions
}

\author{
Giuseppina Turturici · Fabiana Geraci • \\ Maria Elena Candela • Giovanni Giudice • \\ Fidelina Gonzalez · Gabriella Sconzo
}

Received: 21 July 2008/Accepted: 16 September 2008/Published online: 8 October 2008

(C) Springer Science+Business Media B.V. 2008

\begin{abstract}
Mouse A6 mesoangioblasts express Hsp70 even in the absence of cellular stress. Its expression and its intracellular localization were investigated under normal growth conditions and under hyperthermic stress. Immunofluorescence assays indicated that without any stress a fraction of Hsp70 co-localized with actin microfilaments, in the cell cortex and in the contractile ring of dividing cells, while the Hsc70 chaperone did not. Hsp70 immunoprecipitation assays confirmed that a portion of Hsp70 binds actin. Immunoblot assays showed that both proteins were present in the nucleus. After heat treatment Hsp70 and actin continued to co-localize in the leading edge of A6 cells but not on microfilaments. Although Hsp70 and Hsc70 are both basally synthesized they showed different cellular distribution, suggesting an Hsp70 different activity respect to the Hsc70 chaperone. Moreover, we found Hsp70 in the culture medium as it has been described in other cell types.
\end{abstract}

Keywords $\mathrm{Hsp70} \cdot \mathrm{Hsc70} \cdot$ Mesoangioblast cells · Actin

Giuseppina Turturici and Fabiana Geraci contributed equally to this work.

G. Turturici · F. Geraci · M. E. Candela - G. Giudice ·

F. Gonzalez · G. Sconzo ( $\square)$

Dipartimento di Biologia Cellulare e dello Sviluppo, Università

di Palermo, Viale delle Scienze, 90128 Palermo, Italy

e-mail: gasc@unipa.it

Present Address:

F. Gonzalez

Departamento de Biologia Celular Facultad de Ciencias Biológicas, Universidad de Concepción, Casilla 160-C,

Concepcion, Chile

\section{Introduction}

The exposure to environmental, pathological and physiological stresses activates a cellular protective mechanism involving the rapid and transient synthesis of heat shock proteins (Hsps). This cellular response is primarily mediated at transcriptional level by the heat shock transcription factor (HSF). The Hsps are highly conserved among all the organisms and are classified into different families on the basis of molecular mass and one of the most conserved is Hsp70 which is found in every organism examined (Kiang and Tsokos 1998; Tytell and Hooper 2001) and can function as molecular chaperone. Hsp70 prevents protein aggregation and, by transient association of its peptide binding domain with short hydrophobic segments within their target proteins (Mayer and Bukau 2005), it keeps proteins in a competent state either for refolding or for degradation (Kampinga 2006). Some members of the family are constitutively expressed (Hsc70), while some others are generally induced by environmental stress (Hsp70), but a long line of experimental evidence shows that Hsp70 is constitutively and abundantly expressed in many tumour cell lines, even in the absence of stress. Both Hsc70 and Hsp70 participate in the folding of nascent proteins, refolding of mature proteins (Hartl 1996; Ahsen 1997) and the translocation of proteins from one compartment to another (Glick 1995). Hsp70 can also be induced by immortalizing products of the adenovirus E1A 13S (Williams et al. 1989). In some other circumstances Hsp70 can be synthesized under physiological growth conditions, i.e., embryo development (D'Souza and Brown 1998) or some adult tissues which express the protein without any metabolic stress, such as normal colon (Beck et al. 1995) or gerbil ependymal cells lining brain ventricles (Kurucz et al. 1999). More and more data suggest that 
Hsp70 may have different roles than just that of molecular chaperone. Some recent works have demonstrated that in the same way different $\mathrm{Hsp} 70$ isoforms are highly expressed in several human embryonic stem cell lines (Bhattacharya et al. 2004; Abeyta et al. 2004). Many data indicate that its function depends on its spatial location and partner recruitment (Rassow et al. 1995). In fact, immunological assays on several cell lines have demonstrated that Hsp70 shows up in different locations depending on the physiological state of the cell. At normal growth temperature Hsp70 is mainly located in the cytoplasm (Neri et al. 1995; Knowlton 2001) and in some cases in the nucleus, while after heat shock it translocates from the cytoplasm to the nucleus and to the nucleoli (Knowlton 2001; Nollen et al. 2001). After the stress Hsp70 turns back to the cytoplasm (Velazquez and Lindquist 1984; Welch and Feramisco 1984; Rada et al. 2005). Heat shock also induces a reorganization of the cytoskeleton with consequent changes in cellular shape and actin, in the same way of Hsp70, migrates into the nucleus (Wang et al. 1998; Welch and Mizzen 1988). Hsc70 is also a cytoplasmic protein and it translocates within the nucleus after heat shock (Lagunas et al. 2004).

Although Hsps have primarily intracellular functions more reports demonstrates that it also functions extracellularly. The first evidence for this Hsp70 function was suggested in 1980s, when it was shown to transferred from glial cells to axons and to be released from cultured cells (Tytell et al. 1986; Hightower and Guidon 1989). Recently it has been demonstrated that glial cells release Hsp70 making neurons, which are exposed to the protein more resistant to cell stress (Guzhova et al. 2001; Tytell 2005). The A6 cells, a clone of mouse mesoangioblasts, synthesize the Hsp70 under physiological growth conditions and this synthesis is independent from HSF1 or HSF2, but its role is not yet defined (Geraci et al. 2006). To date not many works have studied Hsp70 localization in mammalian cell lines under physiological growth conditions. Therefore, the aim of the present study was to observe Hsp70 localization both under normal growth conditions and after heat stress, and its subcellular distribution, as a means of addressing possible differences in functions between Hsp70 and Hsc70. Moreover, to elucidate the role of Hsp70 characterizing Hsp70-binding proteins may be helpful.

\section{Materials and methods}

Cell culture and heat shock treatment

Mouse A6 stem cells were grown on collagen I treated plates in Dulbecco modified Eagle medium (DMEM)
(Invitrogen) supplemented with $10 \%$ fetal bovine serum in a humidified $5 \% \mathrm{CO}_{2}$ atmosphere at $37^{\circ} \mathrm{C}$. For heat shock, plates were sealed with parafilm and immersed for $1 \mathrm{~h}$ in a $42^{\circ} \mathrm{C}$ water bath.

\section{Immunofluorescence assays}

A6 cells were grown onto microscope coverslips in 12-well culture plates (Nunc). Cells were washed with phosphate buffer saline (PBS1×, $68 \mathrm{mM} \mathrm{NaCl} ; 34 \mathrm{mM} \mathrm{KCl} ; 4 \mathrm{mM}$ $\mathrm{Na}_{2} \mathrm{HPO}_{4} ; 0.44 \mathrm{mM} \mathrm{CaCl}$; $0.24 \mathrm{mM} \mathrm{MgCl}_{2} ; 0.75 \mathrm{mM}$ $\mathrm{KH}_{2} \mathrm{PO}_{4}$ ) and fixed in $3.7 \%$ formaldehyde for $15 \mathrm{~min}$. After three washes in PBS $1 \times$ cells were permeabilized with $0.1 \%$ Triton X-100 for 5 min. Permeabilized cells were washed and incubated over night at $4{ }^{\circ} \mathrm{C}$ with primary antibodies. A rabbit polyclonal anti-Hsp70 (1:1,000; Calbiochem) was used to detect HSP70; a monoclonal mouse anti-Hsc70 (1:500; Santa Cruz) was used to detect HSC70; fluorescein-conjugated phalloidine $\left(10^{-6} \mathrm{M}\right.$; Sigma) was used to detect actin. The secondary antibodies used were fluorescein-conjugated anti-mouse (1:50; Amersham), tetramethylrodamine B isothiocyanate (TRITC)-conjugated anti-rabbit (1:400; Sigma), fluorescein-conjugated antirabbit (1:50; Amersham).

During mitosis dividing cells round up and adhere much less firmly to the surface and this property was used to harvest the mitotic cells from randomly dividing populations of A6 cells. Dividing cells were fixed $45 \mathrm{~min}$ at $37^{\circ} \mathrm{C}$ in MTSB buffer pH 6.9 (0.1 M PIPES; $5 \mathrm{mM} \mathrm{MgCl}_{2}$; $2.5 \mathrm{mM}$ EGTA) supplemented with $1 \mu \mathrm{M}$ paclitaxel; $4 \%$ paraformaldehyde; $0.01 \%$ aprotinin; $1 \mathrm{mM}$ DTT; $0.1 \%$ Triton X-100. Cells were washed in $0.1 \mathrm{M}$ glycine in PBS1X and bound to poly-L-lysine glass by citocentrifugation. Cells were incubated $1 \mathrm{~h}$ in glycine $0.1 \mathrm{M}$ in PBS1X with BSA $0.3 \%$ and then incubated over night with the appropriate first antibodies, followed by $1 \mathrm{~h}$ incubation at room temperature with secondary antibodies. Nucleic acids were stained with $0.2 \mu \mathrm{M}$ propidium iodide. The slides were mounted with 1,4-diazobicycloro[2-2-2] octane and observed by laser scanning confocal microscopy (1X70-S1F2, Olympus) at 498 and $544 \mathrm{~nm}$ wavelengths.

Image analysis was performed using Fluoview 3.3 Software.

Preparation of total and subcellular extracts

Total protein extracts were prepared as previously described (Geraci et al. 2006). For subcellular extracts trypsinized cells were harvested and washed in PBS. Cells were incubated $15 \mathrm{~min}$ on ice in $10 \mathrm{mM}$ HEPES; $10 \mathrm{mM}$ $\mathrm{KCl}, 0.2 \mathrm{mM}$ EDTA; $3 \mathrm{mM} \mathrm{MgCl}_{2} ; 1 \mathrm{mM}$ DTT; $1 \mathrm{mM}$ PMSF; anti-protease cocktail, pH 7.9 and then 10\% NP40 was added. Cells were passed through a 21 gauge needle. 
Nuclear pellet was harvested by centrifugation at $1,000 \mathrm{rpm}$ for $10 \mathrm{~min}$. The supernatant was collected as cytosolic fraction. The nuclear pellet was resuspended in $20 \mathrm{mM}$ HEPES; $400 \mathrm{mM} \mathrm{NaCl}$; $1 \mathrm{mM}$ EDTA; $1 \mathrm{mM}$ EGTA; $1 \mathrm{mM}$ DTT; $1 \mathrm{mM}$ PMSF, pH 7.9; anti-protease cocktail (Sigma) by vortexing for $30 \mathrm{~min}$ at $4{ }^{\circ} \mathrm{C}$. Nuclear debris were discarded by centrifugation at $17,000 \mathrm{rpm}$ for 5 min. Protein concentration of each fraction was determined by Bradford method (Sigma).

\section{Western blot (immunoblot) analysis}

Isolated proteins were subjected to a $10 \%$ SDS-PAGE and transferred to an ECL-Hybond membrane (Amersham) using a mini-electroblot (Biorad).

After blocking for $2 \mathrm{~h}$ in $5 \%$ nonfat dry milk in TBST buffer (10 mM Tris- $\mathrm{HCl}, \mathrm{pH} 7.5,150 \mathrm{mM} \mathrm{NaCl} ; 0.2 \%$ Tween 20), the membranes were incubated over night with rabbit polyclonal anti-Hsp70 (1:10,000; Calbiochem), mouse anti-Hsc70, mouse anti-actin (1:1,500; Neomarkers), goat anti-actin (1:200; Santa Cruz), mouse antitubulin (1:1,000; Sigma). Alkaline phosphatase-conjugated anti-rabbit, anti-mouse (1:5,000; Promega) and anti-goat (1:5,000; Sigma) were used as secondary antibodies.

\section{Immunoprecipitation of protein $\mathrm{Hsp} 70$}

Cells were collected by flasks and washed once in ice-cold PBS. Samples were incubated with cell PBST buffer (PBS: $137 \mathrm{mM} \mathrm{NaCl} ; 2.7 \mathrm{mM} \mathrm{KCl} ; 1.4 \mathrm{mM} \mathrm{NaH} \mathrm{PO}_{4} ; 4.3 \mathrm{mM}$ $\mathrm{Na}_{2} \mathrm{HPO}_{4}$, pH 7.4 with $0.1 \%$ Triton X-100, $0.5 \mathrm{mM}$ DTT and $0.5 \mathrm{mM}$ PMSF) for $10 \mathrm{~min}$ at room temperature. After centrifugation at $13,000 \mathrm{rpm}$ for $5 \mathrm{~min}$ supernatant was collected and determined. $500 \mu \mathrm{g}$ sample were incubated overnight at $4^{\circ} \mathrm{C}$ with anti-Hsp70 antibody $2 / 500 \mu \mathrm{g}$ of samples in PBST. Immune complexes were collected by incubation with $30 \mu \mathrm{l}$ protein G-Sepharose for $4 \mathrm{~h}$ at $4^{\circ} \mathrm{C}$. $\mathrm{G}-$ Sepharose protein was pretreated overnight at $4^{\circ} \mathrm{C}$ with BSA $1 \mathrm{mg} / \mathrm{ml}$. Following antibody binding and protein G-Sepharose absorption, protein G-Sepharose pellets were washed twice with PBST for $5 \mathrm{~min}$. Immune complexes were eluted with $50 \mu \mathrm{l}$ of SB1X (2\% SDS; $10 \%$ glycerol; $0.06 \mathrm{M}$ Tris $\mathrm{pH} 6.8 ; 5 \% \quad \beta$-mercaptoethanol and $0.05 \%$ bromophenol blue) and then boiled.

\section{Scanning electron microscopy}

For scanning electron microscopy cells on coverslips were washed with PBS and fixed in $4 \%$ glutaraldehyde in D-MEM at room temperature for $10 \mathrm{~min}$. Subsequently, cells were washed with D-MEM and dehydrated in an acetone series, mounted on a stub, coated with gold and examined by a Philips $505 \mathrm{SEM}$ at $20 \mathrm{kV}$.
Trypan blue dye exclusion

To measure viability, cells were stained with trypan blue dye and then counted, as described elsewhere (McClowskey et al. 1998).

\section{Results}

In non-stress conditions some of the Hsp70 co-localizes with $\mathrm{F}$ actin

In our study we investigated whether or not Hsp70 and Hsc70 had the same distribution inside the cell and in particular we observed if there was an association with cytoskeletal actin. For this reason we performed double fluorescence assays to observe by confocal microscope actin filamentous network and Hsp70/Hsc70 localization. Actin microfilaments (MFs), stained by fluorescein-conjugated phalloidin, were distributed in two major areas. Some actin was associated with the cell cortex and another part formed cytoplasmic parallel bundles (Fig. 1A a, d). Hsp70 immunofluorescence showed a similar distribution (Fig. 1A b) and the coincidence between the two proteins was confirmed by fluorescence merge (Fig. 1A c). On the contrary, Hsc70 immunofluorescence did not show any fibrillar structure (Fig. 1A e) and did not coincide with that of actin (Fig. 1A f). No co-localization between $\mathrm{Hsp} 70$ and $\beta$-tubulin was observed (Fig. 1A m). Hsp70 co-localized with actin also in the contractile ring at the end of mitotic cell division (Fig. 1A i) different from Hsc70 which was not present in this structure (Fig. 1A k). The immunofluorescence assays indicated that Hsp70 have a different cytoplasmic location respect to $\mathrm{Hsc70}$. We have identified Hsp70-associated protein by nondenaturing immunoprecipitation (Milarski et al. 1989) confirming Hsp70 co-localization with cytoskeletric actin. In fact, an immunoreactive band corresponding to actin was detected in a sample immunoprecipitated with anti-Hsp70 antibodies (Fig. 2 lane 2). As expected no $\beta$-tubulin was detected after immunoprecipitation (Fig. 2 lane 2). This experiment not only confirms the immunofluorescence assays, but also demonstrates that there is a physical interaction between Hsp70 and actin.

Fluorescence staining with scanning through a z-series on the confocal microscope also showed that actin, Hsp70 and Hsc70 were inside the nucleus (data not shown). This subcellular localization was confirmed by immunoblot analysis on nuclear lysates after cell fractionation (Fig. 3A a, b, lane 1). Thus, in normal cells a proportion of Hsp70 and Hsc70 was found inside the nuclei, although they were located mainly in the cytoplasm (Fig. 3A a, b, lane 2). The presence of actin into nucleus has been found in other cell lines independently of Hsp70/Hsc70 (Pederson and Aebi 2002). 
Fig. 1 A Localization of actin, tubulin, Hsp70 and $\mathrm{Hsc70}$ in normal A6 stem cells. (a, d, g, j) Actin distribution. Fluorescence staining with fluoresceinconjugated phalloidine was performed. (b, h) Hsp70 distribution.

Immunofluorescence staining with antibodies against Hsp70 was performed. (c, i)

Fluorescence merge. Filled triangle indicates the contractile ring. (e, k) Hsc70 distribution. Immunofluorescence staining with antibodies against Hsc70 was performed. (f, l)

Fluorescence merge. (m) Fluorescence merge of Hsp70 and tubulin. B Morphological changes of heat-shocked A6 cells. A6 cells were heatshocked at $42^{\circ} \mathrm{C}$ for $1 \mathrm{~h}$ and allowed to recover under normal growing conditions for up $5 \mathrm{~h}$. The cells were fixed and processed for scanning electron microscope and viewed by a Philips SEM at $20 \mathrm{kV}$. (a)

Untreated control cells. (b) Immediately following the heat shock treatment. (c) $5 \mathrm{~h}$ after the heat shock treatment. Shown are typical photographs from three independent experiments. C Immunofluorescence localization of actin (a) and (b) Hsp70 in heat-shocked (1 h at $42^{\circ} \mathrm{C}$ ) A6 stem cells. (c) Fluorescence merge. (d) Immunofluorescence localization of Hsc70 in heatshocked $\left(1 \mathrm{~h}\right.$ at $\left.42^{\circ} \mathrm{C}\right) \mathrm{A} 6$ stem cells. Shown are typical photographs from three independent experiments. Magnification $60 \times$
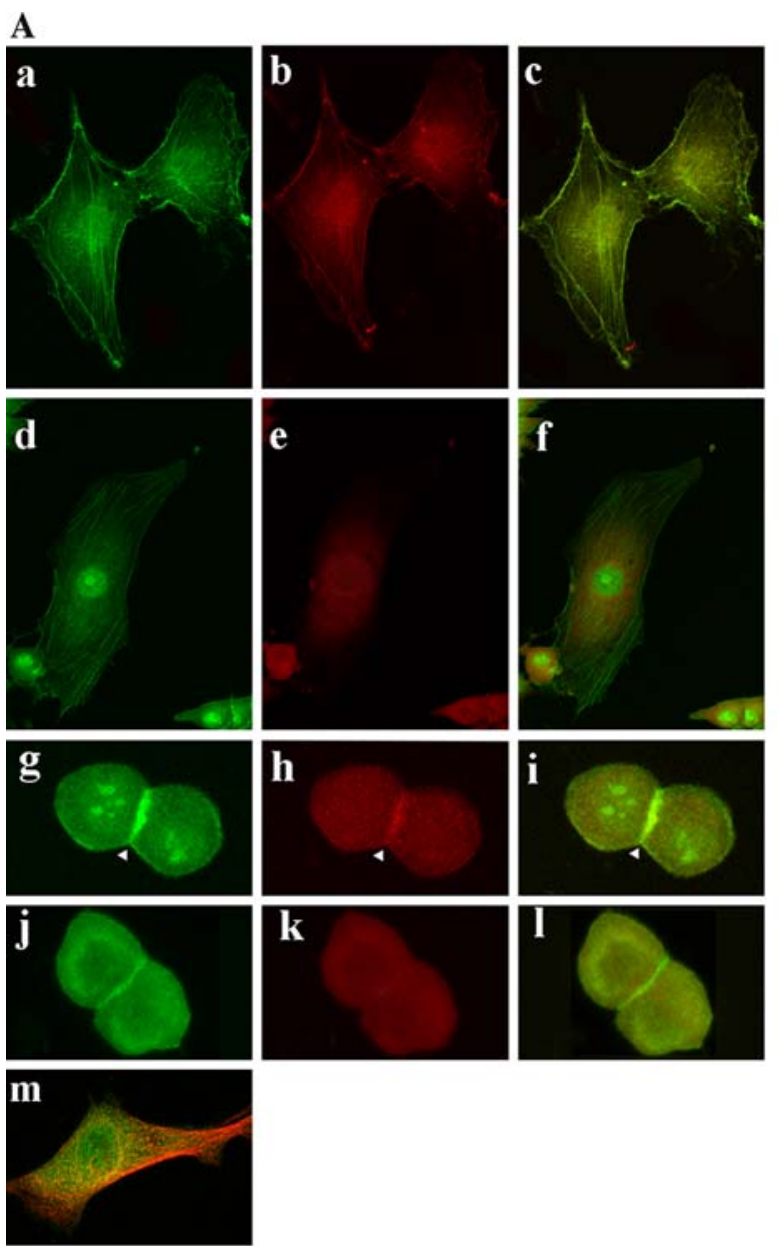

B
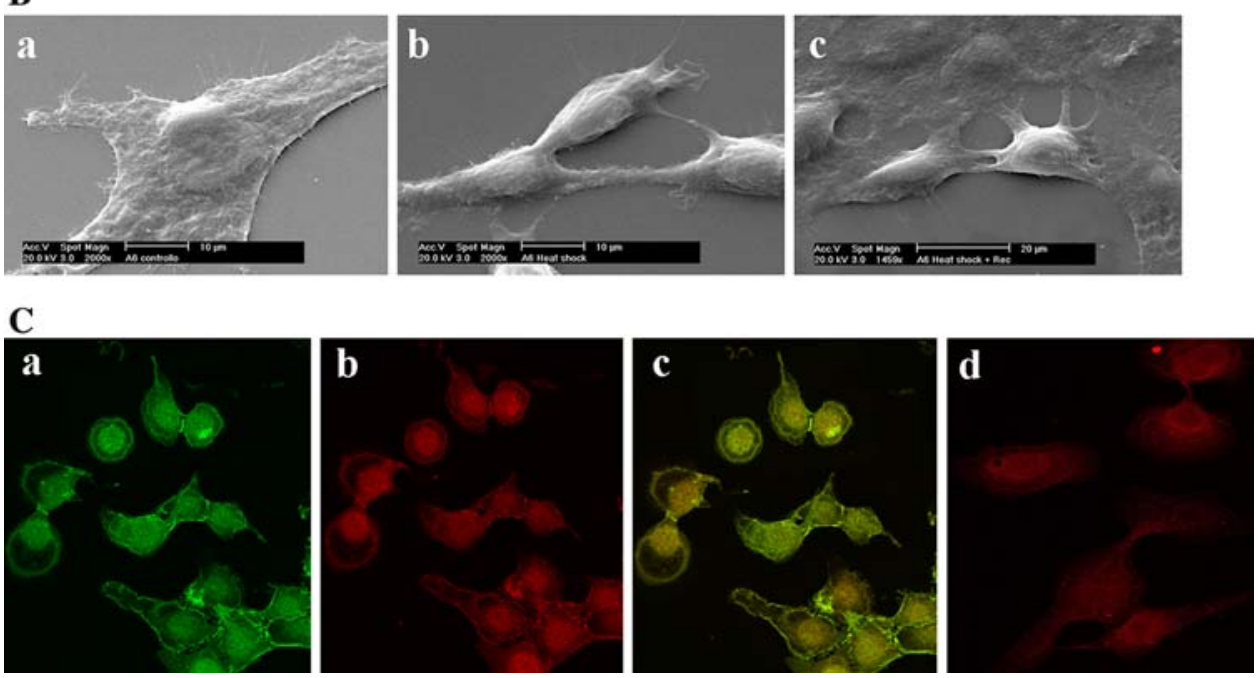

Hsp70 localization during cell divisions

Hsp70 distribution was also studied during mitotic division in cells synchronized by mitotic detachment. During mitotic rounding up Hsp70 localization appeared to be different (Fig. 4a, b) with respect to that of asynchronous population of A6 cells (see Fig. 1A b) and that of Hsc70 during mitotic rounding up (Fig. 4e). The fluorescence, granular in its appearance, was evenly distributed in the cells but it was brighter near the cell cortex and Hsp70 bundles were no more visible (Fig. 4a, b). Densitometric analysis of Hsp70 fluorescence along a diameter of the cell 


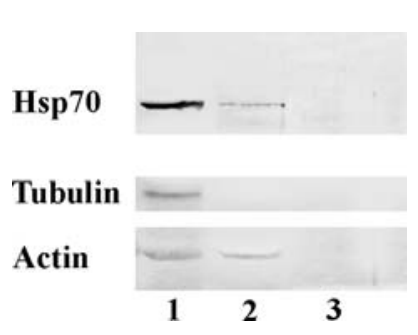

Fig. 2 The Hsp70-interacting protein complexes were immunoprecipitated by anti-Hsp70 antibody. Lane 1 Western blotting of cytoplasmatic extracts of A6 cells with anti-Hsp70, anti-actin and anti-tubulin antibodies as control. Lane 2 immunoprecipitation was performed with anti-Hsp70 antibody and immunoblotted with antiHsp70 (top panel), anti-tubulin (central panel) and anti-actin (bottom panel) antibodies. Lane 3 sample treated without anti-Hsp70 antibody and immunoblotted with anti-Hsp70 (top panel), anti-actin (central panel) and anti-tubulin (bottom panel) antibodies

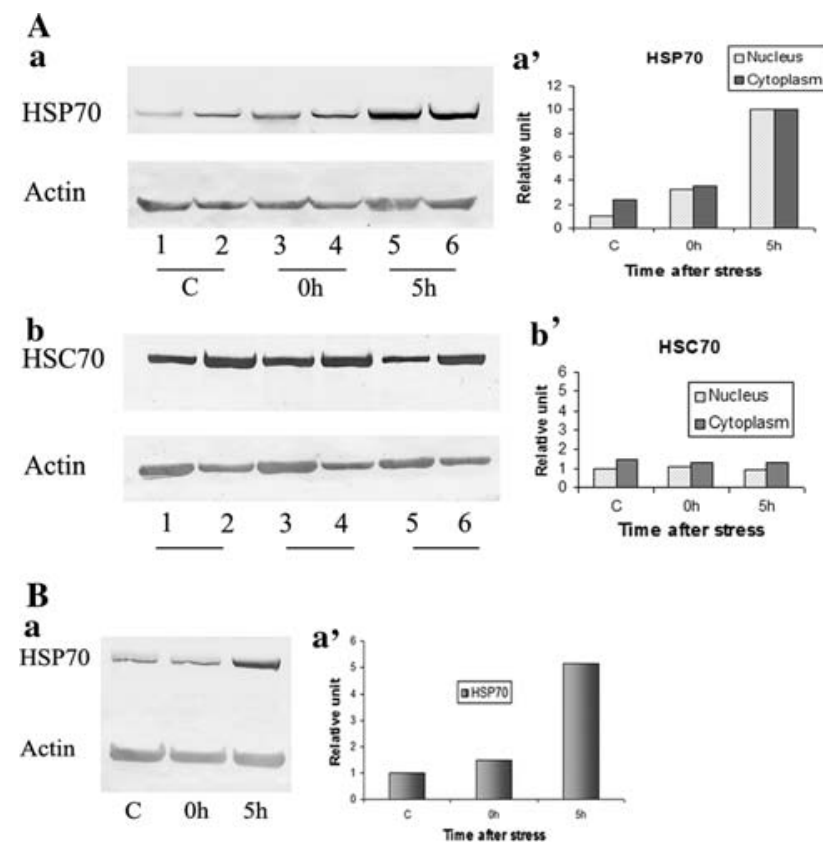

Fig. 3 A Nuclear and cytoplasmatic localization of Hsp70, Hsc70 and actin. (a) Subcellular localization of Hsp70 and actin in normal, heat-shocked and recovering A6 nuclear and cytoplasmatic extracts. A6 cells (control or heat treated) were subfractioned into nucleus and cytoplasm. Aliquots were analyzed for the distribution of Hsp70 by immunoblotting. (a') Data obtained after quantification of immunoreactive bands by Image $\mathbf{J}$ software. (b) Subcellular localization of Hsc70 and actin in normal, heat-shocked and recovering A6 nuclear and cytoplasmatic extracts. A6 cells (control or heat treated) were subfractioned into nucleus and cytoplasm. Aliquots were analyzed for the distribution of Hsc70 by immunoblotting. (b') Data obtained after quantification of immunoreactive bands by Image $\mathbf{J}$ software. Lanes 1 , 3, 5 nuclear fraction; lanes 2, 4, 6 cytoplasmatic fraction. C, non stressed cells; $0 \mathrm{~h}$, immediately after heat shock; $5 \mathrm{~h}, 5 \mathrm{~h}$ after heat shock. Data are obtained from three independent experiments. B (a) Immunoblotting analysis of Hsp70 and actin in normal, heat-shocked and recovering A6 stem cells. (a') Data obtained after quantification of immunoreactive bands by Image $\mathbf{J}$ software. The relative levels of Hsp70 were obtained as the sum of pixel values of each band divided by that of actin in the same lane (internal control) clearly confirmed that Hsp70 is much more concentrated near the cell cortex (Fig. 4c, d). On the contrary, the molecular chaperone Hsc70 although showed a similar pattern of diffused staining (Fig. 4f), did not concentrate near the cell cortex, as demonstrated by densitometric analysis (Fig. 4g). These findings indicated that during mitotic division only Hsp70, and not Hsc70, is clearly located near the cell membrane.

All these data together confirmed that Hsp70 and Hsc70 have a different intracellular localization maybe due to different interactions with cytoskeleton and to different cellular functions.

\section{Hsp70 localization in heat-shocked A6 cells}

Our previous data demonstrated that even if A6 stem cells synthesize Hsp70 without any stress in an HSF1 independent way, they are able to respond to cellular stresses by increasing its level (Geraci et al. 2006). In order to evaluate whether or not Hsp70 distribution was modified after heat treatment, double fluorescence assays have been performed. Before studying Hsp70 localization in heat treated A6 cells, we examined their morphology by using scanning electron microscopy. Figure 1B b, c shows the morphological changes of A6 cells after heat shock treatment. Before heat shock the cells appear well spread on substratum (Fig. 1B a). Immediately after heat shock the most of the cytoplasm is contracted to the cell centre and a thin layer remains attached to the substratum (Fig. 1B b). Five hours after heat shock the cells gradually spread outwards and assumed their normal appearance (Fig. 1B c). These changes in cellular shape were due to cytoskeleton reorganization, as confirmed by immunofluorescence. In fact, immediately after heat shock $\left(42^{\circ} \mathrm{C}, 1 \mathrm{~h}\right)$ actin MFs were no more visible, while a brighter fluorescence remained in the peripheral regions of the cell (Fig. 1C a). The same immunofluorescent pattern was detected for Hsp70, with a brighter fluorescence near the cell membrane and an increased immunopositivity near and inside the nucleus (Fig. 1C b). The two proteins soon after heat treatment appeared to have the same staining distribution (Fig. 1C c). We also observed Hsc70 distribution after heat shock. In contrast to resting cells differences between Hsp70 and Hsc70 were less evident after heat stress. The most relevant difference regarded their presence at/or near the cell surface. Differently from Hsp70, Hsc70 did not show any peripheral staining (Fig. 1C d). Moreover, immediately after heat shock by immunoblot analysis it was not possible to detect a consistent Hsp70 increase respect to its basal level, while a higher increase in its level was observed $5 \mathrm{~h}$ after heat treatment (Fig. 3B a, a'). Cell fractionation experiments showed that the hyperthermic stress led the gradual increase of both nuclear and cytoplasmic Hsp70 

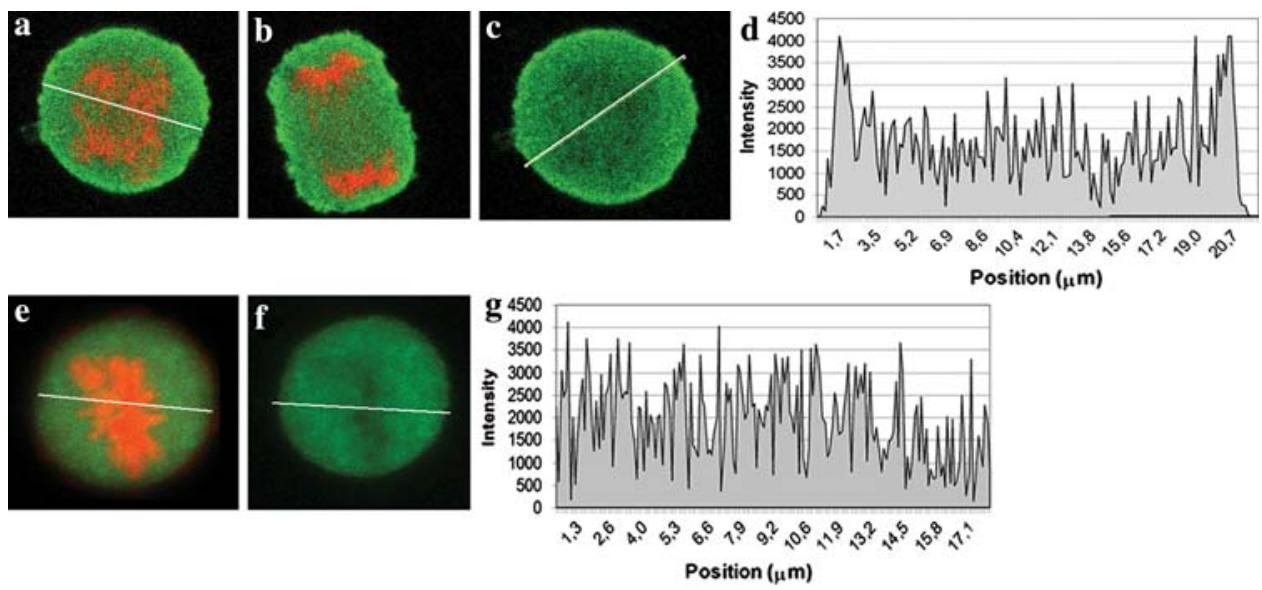

Fig. 4 Hsp70 distribution in A6 mitotic cells. (a, b) Immunofluorescences of two different mitotic phases are shown. Chromosomes are visualized by propidium iodide staining (red). c Hsp70 immunofluorescence (green) quantification along the showed diameter of the cell, obtained by Software Fluoview 3.3. d Histograms of fluorescence intensity showed increased Hsp70 staining in the cell cortex.

level (Fig. 3A a, lanes 3-4) and this increase in both cellular compartments was more evident $5 \mathrm{~h}$ after the heat shock (Fig. 3A a, lanes 5-6), confirming as expected Hsp70 movement towards the nucleus. Hsc70 immunoblot analysis on the same cell lysates showed that the Hsc70 level did not increase during the heat stress or the recovery (Fig. 3A b').

Hsp70 in the extracellular space

As previously shown by others, a fraction of Hsp70, normally localized to the cytoplasm or nucleus, can be released in the extracellular space from cells and function as intercellular-signaling ligands (Asea et al. 2000). For example Hsp70 is a normal constituent of blood and its levels changes with physiological stress and disease (Lancaster and Febbraio 2005). According to this emerging data we examined Hsp70 presence in the culture medium to test a possible release of this protein into extracellular space. Western blot assay of the medium demonstrated its

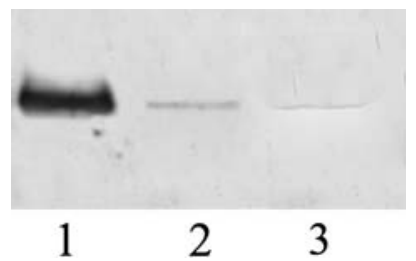

Fig. 5 Hsp70 presence in the culture medium of A6 cells. Supernatant from cell cultures was recovered, centrifuged to clear floating cells and debris. Hsp70 presence was demonstrated by western blot analysis. Lane 1 cell lysate, lane 2 culture medium with serum and lane 3 culture medium without serum
Immunoreactive Hsp70 was mainly observed in the cell cortex. e Hsc70 distribution in mitotic cells. Chromosomes are visualized by propidium iodide staining (red). f Hsc70 immunofluorescence (green) quantification along the showed diameter of the cell obtained by Software Fluoview 3.3. g Histograms of fluorescence intensity showed a uniform Hsc70 distribution in the cell

presence (Fig. 5 lane 2). Hsp70 has also been found in serum-free medium (Fig. 5 lane 3). This release was not due to necrosis as cell viability was $98 \%$ (data not shown).

\section{Discussion}

Mouse mesoangioblasts are a novel kind of stem cells distinct from both embryonic (ES) and adult stem cells. They are embryo vessel-derived stem cells which can be propagated in vitro and can be differentiate into different mesoderm derived cell types (Minasi et al. 2002). We have recently studied the stress status of these stem cells in vitro and we have found that they express the inducible form of Hsp70 without any stress independently of HSF1 (Geraci et al. 2006). Differences in function between Hsp70 and Hsc70 may be reflected in differences in their intracellular localization before and after heat stress. For this reason in our study we observed Hsp70 localization. Other previous works have demonstrated that in some cell lines HSP70 is associated with tubulin, with a generic chaperone function (Cheng and Lai 1994; Wang et al. 1998), while in rat embryo fibroblasts it has been found associated with actin microfilaments (La Thangue 1984; Margulis and Welsh 1991a, b). Immunofluorescence studies on A6 stem cells showed that Hsp70 and Hsc70 have a different localization inside the cell, with $\mathrm{Hsp} 70$ primarily associated with microfilaments, and cell cortex. In particular, some of the Hsp70 co-localized under physiological growth conditions with actin microfilament network in asynchronous cells and with contractile ring in mitotic cells. In addition, immunoprecipitations experiments demonstrated that there 
is a physical interaction between Hsp70 and actin not only a co-localization. A different intracellular distribution was evident for the constitutive chaperone Hsc70. In fact, Hsc70 has never been found associated with actin microfilaments or with contractile ring in mitotic cells and in addition it never thickened near the cell membrane. Furthermore no interaction with actin was detected. As expected under heat stress when the cell shape was changed, the fluorescent actin microfilaments disappeared. At the same time Hsp70 filaments were not anymore detected by immunofluorescence assays and the two proteins colocalized near the cell plasma membrane, confirming Hsp70 and actin co-localization. We may conclude that Hsp70 and Hsc70, although they are both synthesized under basal growth conditions, differ with respect to their pattern of distribution and this may reflect different functions. In this study we also demonstrated that some of the Hsp70 was released in the extracellular milieu. A recent paper on plant virus demonstrated that microfilaments are involved in transporting Hsp70 h, an homologue of cellular Hsp70 (Prokhnevsky et al. 2005). The absence of a consensus secretory signal in Hsp70 and its association with actin prompt us to hypothesize a possible involvement of actin in Hsp70 release.

Acknowledgements This research was supported by Italian Murst (60\%). We wish to thank Mr Giovanni Morici for densitometric analys of fluorescence and Dr Francesco Carfî Pavia for SEM images.

\section{References}

Abeyta MJ, Clark AT, Rodriguez RT et al (2004) Unique gene expression signatures of independently-derived human embryonic stem cell lines. Hum Mol Genet 13:601-608. doi:10.1093/ hmg/ddh068

Ahsen P (1997) Molecular chaperones: towards a characterization of the heat-shock protein 70 family. Trends Cell Biol 7:129-133. doi:10.1016/S0962-8924(96)10056-8

Asea A, Kraeft SK, Kurt-Jones EA et al (2000) HSP70 stimulates cytokine production through a CD14-dependant pathway, demonstrating its dual role as a chaperone and cytokine. Nat Med 6:435-442. doi:10.1038/74697

Beck SC, Paidas CN, Mooney ML et al (1995) Presence of the stressinducible form of hsp-70 (hsp-72) in normal rat colon. Shock 3:398-402. doi:10.1097/00024382-199506000-00003

Bhattacharya B, Miura T, Brandenberger R et al (2004) Gene expression in human embryonic stem cell lines: unique molecular signature. Blood 103:2956-2964. doi:10.1182/blood-200309-3314

Cheng TJ, Lai YK (1994) Transient increase in vimentin phosphorylation and vimentin-HSC70 association in 9L rat brain tumor cells experiencing heat-shock. J Cell Biochem 54:100-109. doi: 10.1002/jcb.240540111

D’Souza SM, Brown IR (1998) Constitutive expression of heat shock proteins Hsp90, Hsc70, Hsp70 and Hsp60 in neural and nonneural tissues of the rat during postnatal development. Cell Stress Chaperones 3:188-199. doi:10.1379/1466-1268(1998) $003<0188:$ CEOHSP $>2.3 . \mathrm{CO} ; 2$
Geraci F, Turturici G, Galli D et al (2006) Stress response in mesoangioblast stem cells. Cell Death Differ 13:1057-1063. doi: 10.1038/sj.cdd.4401794

Glick BS (1995) Can Hsp70 proteins act as force-generating motors? Cell 80:11-14. doi:10.1016/0092-8674(95)90444-1

Guzhova I, Kislyakova K, Moskaliova O et al (2001) In vitro studies show that Hsp70 can be released by glia and that exogenous Hsp70 can enhance neuronal stress tolerance. Brain Res 914:6673. doi:10.1016/S0006-8993(01)02774-3

Hartl FU (1996) Molecular chaperones in cellular protein folding. Nature 381:571-579. doi:10.1038/381571a0

Hightower LE, Guidon PT Jr (1989) Selective release from cultured mammalian cells of heat-shock (stress) proteins that resemble glia-axon transfer proteins. J Cell Physiol 138:257-266. doi: 10.1002/jcp. 1041380206

Kampinga HH (2006) Chaperones in preventing protein denaturation in living cells and protecting against cellular stress. Handb Exp Pharmacol 172:1-42. doi:10.1007/3-540-29717-0_1

Kiang JG, Tsokos GC (1998) Heat shock protein 70 kDa: molecular biology, biochemistry, and physiology. Pharmacol Ther 80:183201. doi:10.1016/S0163-7258(98)00028-X

Knowlton AA (2001) Mutation of amino acids 566-572 (KKKVLDK) inhibits nuclear accumulation of heat shock protein 72 after heat shock. J Mol Cell Cardiol 33:49-55. doi: 10.1006/jmcc. 2000.1274

Kurucz I, Tombor B, Prechl J, et al (1999) Ultrastructural localization of Hsp-72 examined with a new polyclonal antibody raised against the truncated variable domain of the heat shock protein. Cell Stress Chaperones 4:139-152. doi:10.1379/14661268(1999)004<0139:ULOHEW>2.3.CO;2

Lagunas L, Bradbury CM, Laszlo A et al (2004) Indomethacin and ibuprofen induce Hsc70 nuclear localization and activation of the heat shock response in HeLa cells. Biochem Biophys Res Commun 313:863-870. doi:10.1016/j.bbrc.2003.12.018

La Thangue NB (1984) A major heat-shock protein defined by a monoclonal antibody. EMBO J 3:1871-1879

Lancaster GI, Febbraio MA (2005) Exosome-dependent trafficking of HSP70: a novel secretory pathway for cellular stress proteins. J Biol Chem 280:23349-23355. doi:10.1074/jbc.M502017200

Margulis BA, Welsh M (1991a) Isolation of hsp70-binding proteins from bovine muscle. Biochem Biophys Res Commun 178:1-7. doi:10.1016/0006-291X(91)91771-4

Margulis BA, Welsh M (1991b) Analysis of protein binding to heat shock protein 70 in pancreatic islet cells exposed to elevated temperatures or interleukin 1 beta. J Biol Chem 266:9295-9298

Mayer MP, Bukau B (2005) Hsp70 chaperones: cellular functions and molecular mechanism. Cell Mol Life Sci 62:670-684. doi: 10.1007/s00018-004-4464-6

McClowskey TW, Chavan S, Tamma Lakshmi et al (1998) Comparison of seven quantitative assays to assess lymphocytic cell death during HIV infection: measurement of induced apoptosis in antiFas treated Jurkat cells and spontaneous apoptosis in peripheral blood mononuclear cells from children infected with HIV. AIDS Res Hum Retroviruses 14:1413-1422

Milarski KL, Welch WJ, Morimoto RI (1989) Cell cycle-dependent association of HSP70 with specific cellular proteins. J Cell Biol 108:413-423. doi:10.1083/jcb.108.2.413

Minasi MG, Riminucci M, De Angelis L et al (2002) The mesoangioblast: a multipotent, self-renewing cell that originates from the dorsal aorta and differentiates into most mesodermal tissues. Development 129:2773-2783

Neri LM, Riederer BM, Marugg RA et al (1995) Analysis by confocal microscopy of the behaviour of heat shock protein 70 within the nucleus and of a nuclear matrix polypeptide during prolonged heat shock response in HeLa cells. Exp Cell Res 221:301-310. doi:10.1006/excr.1995.1379 
Nollen EA, Salomons FA, Brunsting JF et al (2001) Dynamic changes in the localization of thermally unfolded nuclear proteins associated with chaperone-dependent protection. Proc Natl Acad Sci USA 98:12038-12043. doi:10.1073/pnas.201112398

Pederson T, Aebi U (2002) Actin in the nucleus: what form and what for? J Struct Biol 140:3-9. doi:10.1016/S1047-8477(02)00528-2

Prokhnevsky AI, Peremyslov VV, Dolja VV (2005) Actin cytoskeleton is involved in targeting of a viral Hsp70 homolog to the cell periphery. J Virol 79:14421-14428. doi:10.1128/JVI.79.22. 14421-14428.2005

Rada A, Tonino P, Anselmi G et al (2005) Is hypothermia a stress condition in HepG2 cells? Expression and localization of Hsp70 in human hepatoma cell line. Tissue Cell 37:59-65. doi:10.1016/ j.tice.2004.10.003

Rassow J, Voos W, Pfanner N (1995) Partner proteins determine multiple functions of Hsp70. Trends Cell Biol 5:207-212. doi: 10.1016/S0962-8924(00)89001-7

Tytell M (2005) Release of heat shock proteins (Hsps) and the effects of extracellular Hsps on neural cells and tissues. Int J Hyperthermia 21:445-455. doi:10.1080/02656730500041921

Tytell M, Hooper PL (2001) Heat shock proteins: new keys to the development of cytoprotective therapies. Expert Opin Ther Targets 5:267-287. doi:10.1517/14728222.5.2.267
Tytell M, Greenberg SG, Lasek RJ (1986) Heat shock-like protein is transferred from glia to axon. Brain Res 363:161-164. doi: 10.1016/0006-8993(86)90671-2

Velazquez JM, Lindquist S (1984) Hsp70: nuclear concentration during environmental stress and cytoplasmic storage during recovery. Cell 36:655-662. doi:10.1016/0092-8674(84)90345-3

Wang TT, Chiang AS, Chu JJ et al (1998) Concomitant alterations in distribution of $70 \mathrm{kDa}$ heat shock proteins, cytoskeleton and organelles in heat shocked 9L cells. Int J Biochem Cell Biol 30:745-759. doi:10.1016/S1357-2725(97)00133-7

Welch WJ, Feramisco JR (1984) Nuclear and nucleolar localization of the 72,000-dalton heat shock protein in heat-shocked mammalian cells. J Biol Chem 259:4501-4513

Welch WJ, Mizzen LA (1988) Characterization of the thermotolerant cell. II. Effects on the intracellular distribution of heat-shock protein 70 , intermediate filaments, and small nuclear ribonucleoprotein complexes. J Cell Biol 106:1117-1130. doi:10.1083/ jcb.106.4.1117

Williams GT, McClanahan TK, Morimoto RI (1989) E1a transactivation of the human HSP70 promoter is mediated through the basal transcriptional complex. Mol Cell Biol 9:2574-2587 